\title{
Micro classes as a primary school-level mathematics education response to COVID-19 pandemic in China: students' degree of approval and perception of digital equity
}

\author{
Zhiyong Xie ${ }^{1,2} \cdot$ Leifeng Xiao $^{3} \cdot$ Meiteng Hou $^{1} \cdot$ Xianling Liu $^{4} \cdot$ Jian Liu ${ }^{1}$
}

Accepted: 8 September 2021 / Published online: 6 November 2021

(c) The Author(s), under exclusive licence to Springer Nature B.V. 2021

\begin{abstract}
The article introduces a mathematics education measure in response to the COVID-19 epidemic in China and explores students' degree of approval and perception of digital equity towards the response. After the outbreak of the COVID-19, the Chinese New Century Primary School Mathematics Textbook (NCPM) committee had developed a series of micro classes (abbreviated as NCPM micro classes), and more than 25 million teachers and students in China watched the NCPM micro classes during the 3 months social isolation. Then, students' degree of approval towards the NCPM micro classes and perception of digital equity were examined after social isolation. A total of 132,740 pieces of data were collected from Chinese primary school students. Quantitative analysis of student's degree of approval towards different parts of NCPM micro classes indicated that the introduction, interaction, summary and consolidation, curriculum characteristics, and goal achievement parts of the NCPM micro classes have received high approval from students, and students with higher former achievement perceived a higher degree of approval towards the NCPM micro classes. Furthermore, we found that gender, socioeconomic status, school location, and learning location had no significant impact on students' degree of approval, indicating a digital equity exists. This study helps researchers or educators understand the mathematics education response to the COVID-19 outbreak in China and extends our understanding of primary students' degree of approval and perception of digital equity with these online classes.
\end{abstract}

Keywords COVID-19 $\cdot$ Primary mathematics $\cdot$ Micro classes $\cdot$ Degree of approval $\cdot$ Digital equity

Jian Liu

professorliu9506@126.com

1 Collaborative Innovation Center of Assessment for Basic Education Quality, Beijing Normal University, No. 19 Xin Jie Kou Wai Street, Hai Dian District, Beijing 100875, China

2 School of Mathematics and Computer Science, Gannan Normal University, Ganzhou, Jiangxi, China

3 Department of Educational Psychology, The Chinese University of Hong Kong, Hong Kong, China

4 Primary School Affiliated to Northeast Normal University, Changchun, Jilin, China 


\section{Introduction}

The COVID-19 pandemic, one of the largest catastrophes in the last 10 years in the world (WHO, 2020), has captured the attention of the world's people and their governments and also rapidly upended social and educational systems (Liu et al., 2020). During the epidemic period, working or studying at home has become one of the measures for disease control and prevention (Bedford et al., 2020). As an education response, online learning at home has been implemented instead of traditional learning at school in many countries (Kuhfeld et al., 2020; Moorhouse, 2020). Specifically, in China, the Ministry of Education (MOE) of the People's Republic of China issued the Classes Suspended but Learning Continues notice to encourage students to study at home (MOE, 2020). Since then, online courses, live webcast teaching, student self-study, and TV aerial classrooms have become the four common online learning and teaching modes during the epidemic (Jiao et al., 2020). Meanwhile, the requirement of online instruction time was limited to $2 \mathrm{~h}$ for primary school students and $3 \mathrm{~h}$ for secondary school students (Zhu et al., 2020). Hence, based on the emergency policy of MOE, the committee of Chinese New Century Primary School Mathematics Textbook (NCPM), one of China's mainstream textbooks, invited more than 60 experts (including primary school mathematics curriculum experts, textbook compilation experts, expert teachers, and information technology experts) to develop free access primary school mathematics micro classes (abbreviated as NCPM micro classes), since micro class can fit the required learning time of the emergency policy perfectly. As a kind of modern distance learning and teaching resource, micro classes introduced a specific knowledge point through a short video (Fang \& Liu, 2017; Gong \& Zhu, 2014; Jiang, 2013; Li \& Liu, 2015; Xie, 2015), which has been widely applied in online courses and in blended or flipped learning environments $(\mathrm{Hu}$, 2011; Hu \& Zhan, 2012), especially in mathematics education (Fang \& Liu, 2017).

In terms of learning procedure at the student level, firstly, teachers sent NCPM micro class download links to students through online communication platforms (i.e., WeChat or QQ group) every day. Students could also download and watch them for free from various NCPM platforms, i.e., the NCPM official website, NCPM community APP in mobile, or NCPM WeChat official account. In daily online teaching during the social isolation, teachers arranged students to watch micro classes online first and then answered students' questions through an interactive online teaching platform. Until April 28, 2020, the last day of the social isolation in China, NCPM had updated 385 online courses on multiple platforms. Approximately 25 million people, distributed in all provinces and cities of China, joined and watched these NCPM micro classes, with a total of 257 million clicks from various NCPM platforms (NCPMTEC, ${ }^{12} 2020$ ).

As the widespread use of the NCPM micro classes, it is vital for our designers to know the effects of the NCPM micro classes. Recent studies have found that students' mental state was greatly affected by the social impact of the epidemic at the beginning of the epidemic, and students were not able to adapt to online learning (Kuhfeld et al., 2020; Liu et al., 2020). In addition, the effect of distance learning was unclear since there was a huge gap in acquiring technology in many regions and schools (Kuhfeld et al., 2020). Thus, in the present study, we would investigate students' degree of approval of the NCPM micro classes, which could be regarded as a piece of evidence of the effect of NCPM micro classes.

Furthermore, the debates on educational equity have continued along with the popularization of online learning. Some researchers found that the application of these new technologies increased the existing social stratification and inequality, resulting in a "digital divide" (e.g., Castells, 1996; Van

\footnotetext{
1 New Century Primary School Mathematics Textbook Editorial Committee. Until now, there are 1300 micro classes in total on the website: https://www.xsj21.com/.
} 
Dijk \& Hacker, 2003). Specifically, the imbalance in family digital education resources is expected to enlarge the differences in educational quality and opportunities among different social strata to a great extent, and those with low social strata are expected to become trapped in an invisible digital gap easily (Hsieh et al., 2008). However, others hold an opposite view and approved that online courses have a great potential in reducing educational inequality and promoting educational equity (Adedoyin \& Soykan, 2020; Stephens, 2020). Thus, in the present study, we also want to know students' perception of digital equity after attending the NCPM micro classes; furthermore, we assume, if there would be no difference on students' perceived degree of approval towards the NCPM micro classes among students from different social backgrounds, there would be digital equity.

Thus, the purpose of this research aims to explore students' degree of approval to the NCPM micro classes and perception of digital equity after attending such classes through the investigation by NCPM.

\section{Micro classes as a response to the epidemic}

Micro classes are named as a mini course, micro lecture, micro-lecture, micro lesson, etc.; a new online video course supporting multiple learning methods was designed and developed based on micro-teaching videos. The micro class is a distance learning and teaching resource that uses a short video presentation on a single topic (Fang \& Liu, 2017; Gao et al., 2019; Gong \& Zhu, 2014; Hu, 2011; Hu \& Wen, 2016; Hu \& Zhan, 2012; Jiang, 2013; Li \& Liu, 2015; Xie, 2015). Therefore, in this study, we defined micro class as an online video course designed and developed for a specific knowledge point (i.e., key points and difficult points) or teaching stage (i.e., learning activities, topics, experiments, and tasks), focusing on students' learning. Researchers (e.g., Fang \& Liu, 2017; Gong \& Zhu, 2014; Jiang, 2013; Li \& Liu, 2015; Xie, 2015) have argued that micro classes were characterized by clear goals, unique themes, diverse resources, real situations, and short, sophisticated lessons which were easy to use, semi-structured, and easy to expand. Recently, the micro class has attracted the attention of educators due to these characteristics, especially mathematics education researchers (Fang \& Liu, 2017). Moreover, it has been widely applied in online courses and in blended or flipped learning environments $(\mathrm{Hu}$, 2011; Hu \& Zhan, 2012). Hence, the NCPM committee planned to develop a series of micro classes to respond to the outbreak.

In developing these micro classes, learner-centered education, which has received great popularity since the rise of the Western trend of thought in modern education, was regarded as the developing guide. However, in online learning, learning content cannot be used directly as with the traditional classroom; it is not easy to implement learner-centered education in such a short micro class. Hence, it requires teachers or instructional designers to record, edit, and integrate learning materials with various technologies and reorganize the structure according to the principles of teaching theory or teaching methods. In order to apply learner-centered education thought to micro class, the development of NCPM micro classes entirely based on the NCPM textbook, which took "situation + problem series" as the introductory presentation form to help students think about the core content and key points. Specifically, on the one hand, the micro class learning situation followed some materials from the textbook; on the other hand, the learning materials were adapted from students' real-life experience and to meet students' cognitive demands. The design of micro class encourages realistic and real situations, and the selection of problems is diverse, universal, and challenging to stimulate students' learning motivation and enthusiasm. Given the current home-based learning of primary school students during the epidemic period, 
the NCPM micro class uses offline practice activities with rich material design for primary school students. It provided opportunities for mathematics practice between parents and children to experience practical and broad application of mathematics.

In the face of continuous epidemic prevention and control, children inevitably experience worry, anxiety, loneliness, and other stress reactions. Meanwhile, children may face a lack of interactions or emotional support with such emotionless e-learning tools. Thus, the design of the NCPM micro class also focused on interactions with students and inspiring students' learning interest with many vivid learning materials. Specifically, the videos were made in animation and expressed in children's language with a lovely voice. For example, in the micro class, one of the chief characters, pigsy “八戒” in the Chinese classic story Journey to the West was designed in the learning situation to stimulate children's learning interest.

\section{An illustration of one micro class}

The NCPM micro class provides a series of primary school mathematics micro classes and resources free of charge, starting in mid-February 2020 for all schools using NCPM textbooks from Grade 1 to Grade 6 in China. Now, we take an example of one micro class to show the design of the teaching process. The topic of the example micro class is The Animal's Party, introducing counting and multiplication, which is designed for second grade students (Fig. 1). Details are shown as follows.

Firstly, there is a slide shown in the beginning of the micro class (Fig. 1); then, after that, four parts of the micro class are introduced in a sequence, namely, introduction part, teaching and learning interaction part, and summary and consolidation. The English transcript and Chinese original version are shown as well. Here in the transcript part, Taoqi and Xiaoxiao are the names of two students.

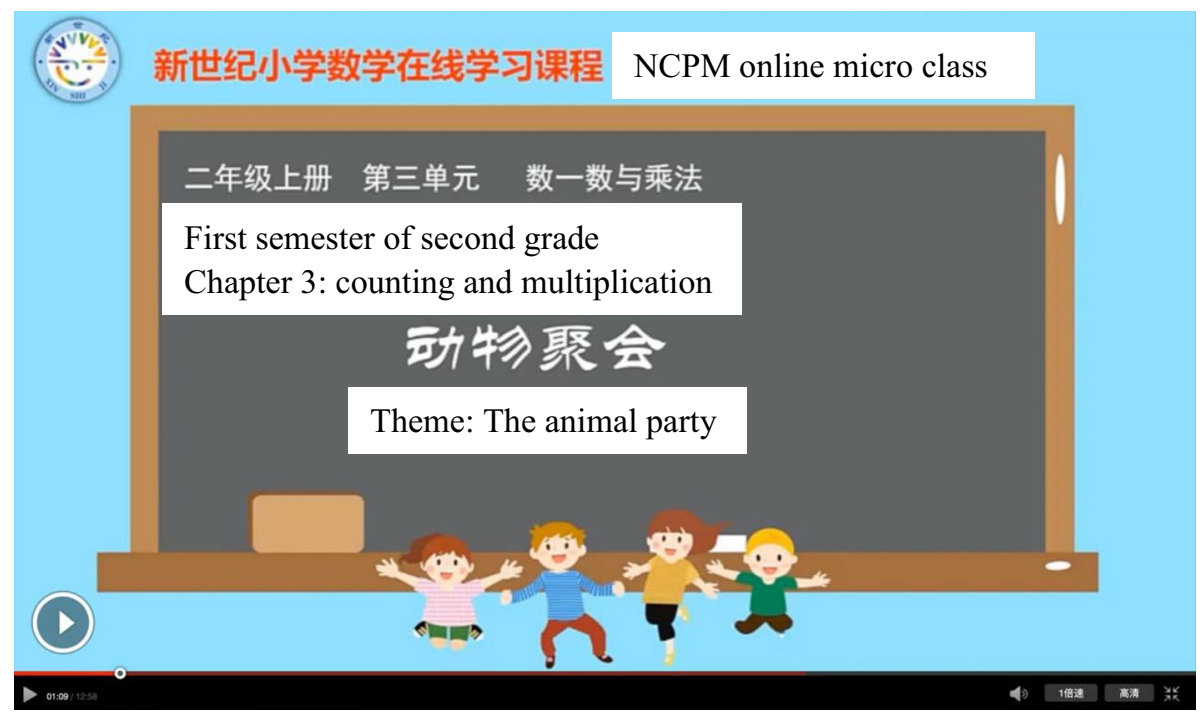

Fig. 1 Micro class topic: the animal party 


\subsection{Introduction part of NCPM micro class}

In the introduction part, the teacher introduces the purpose and achievement goal of the class (see Fig. 2), then the teacher and students have some activities for interaction (see Fig. 3). Teacher and students' recording transcript is showed in the following.

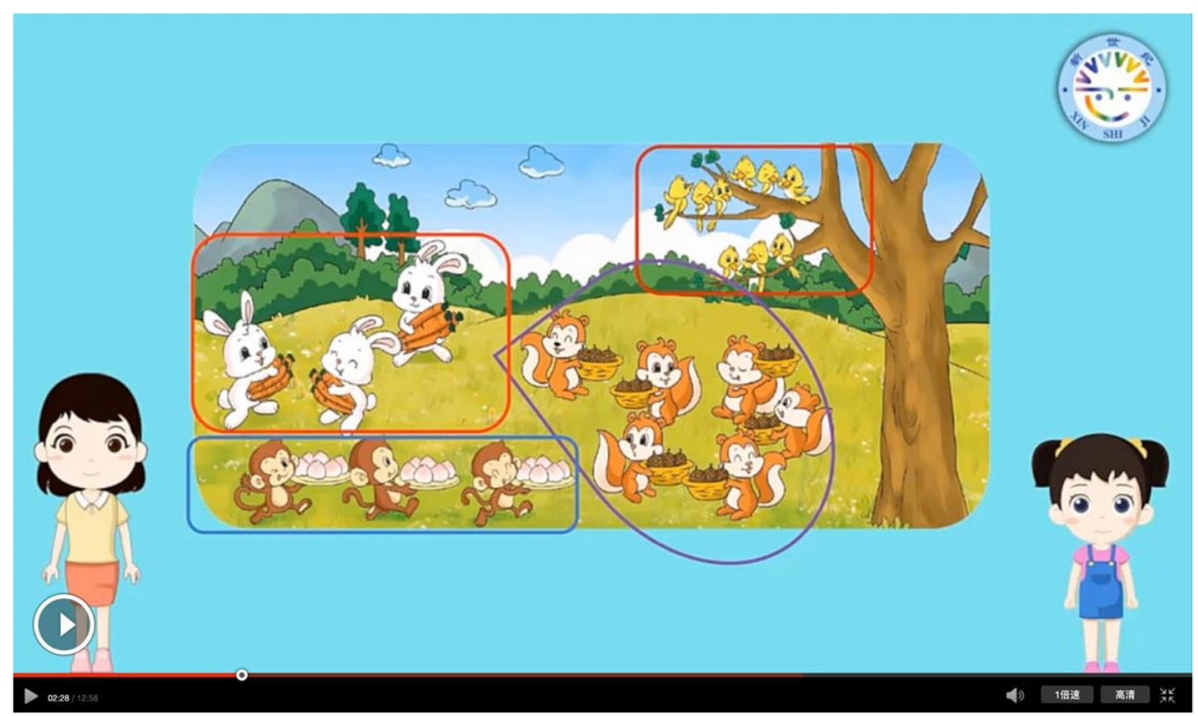

Fig. 2 Micro class introduction

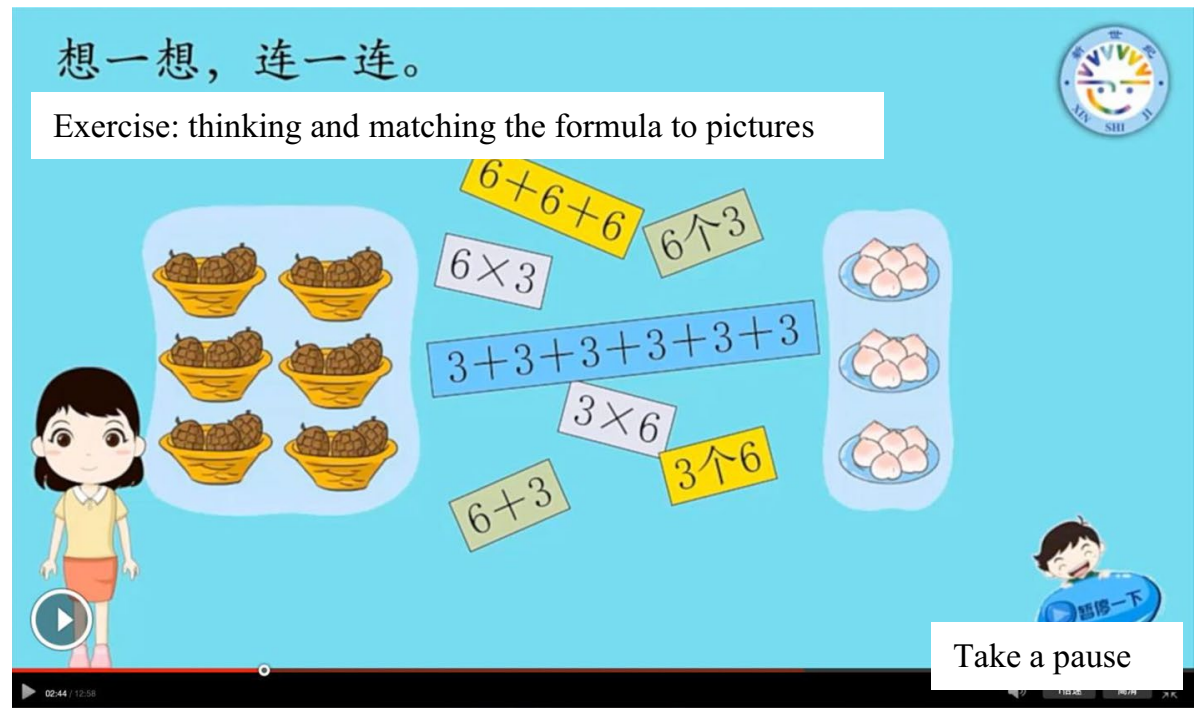

Fig. 3 Teaching and learning interaction of micro classes 
English Transcript

Teacher: Hello, everyone. In today's study, we would achieve two purpose in the course. we need to (1) further understand the relationship between the same number addition formula and multiplication formula in specific situations, and (2) combine with particular examples to realize that the meaning of the same multiplication formula is different in different situations. Well, let's start today's learning journey. Autumn is coming, and the fruits are ripe all over the mountains. The little animals have decided to hold a harvest party. How lively it is. Carefully observe; what do you find? (Figure 2).

[Pause, a few moments latter] Taoqi: I found that there are three rabbits in the picture. Each rabbit has four carrots.

Xiaoxiao: There are three monkeys, each with six peaches.

Taoqi: There are six little squirrels, each carrying three pinecones.

Xiaoxiao: I also found that there are three branches, and three birds stand on each branch.
Chinese Original Version

老师: 大家好! 在今天的学习中, 我们要 （1）结合具体情境, 进一步体会相同数连 加算式与乘法算式之间的关系。（2）结合具 体事例体会同一个乘法算式在不同情境中表 示的意义是不同的.

老师: 好了, 让我们开始今天的学习之旅 吧. 秋天来了, 漫山遍野的果子熟了, 小动 物们决定举行一个庆丰收的联欢会。多热闹 啊! 仔细观察, 你发现了什么?

淘气: 我发现图中有三只小兔子, 每只小兔 子带来了四根胡萝卜。

淘气: 有六只小松鼠, 每只小松鼠带来了三 个松果.

笑笑：我还发现有三根树枝，每根树枝上有 三只鸟. 


\subsubsection{Teaching and learning interaction part}

\section{English Transcript}

Teacher: You are so careful! Here are the pinecones and peaches brought by my little squirrel and a little monkey. Please see the picture (Figure 3). What formula can your mind conceive? Take a pause. Please consider and connect.

Taoqi: Let me look at pinecones. There are three pinecones in each basket. There are six baskets in total. That is to say, six three add, and the addition formula is $3+3+3+$ $3+3+3$.

Xiaoxiao: Six three add can also be written as a multiplication formula, three times six or six times three (connection diagram and formula). There are four corresponding cards.

Xiaoxiao: I found that although these two graphs (pinecones and peaches) are different, they can be written as three times six or six times three. What's the matter?

Taoqi: In the pinecone chart on the left, there are three pinecones in each basket, with a total of six baskets, which can be represented as six threes. In the peach chart on the right, there are six peaches on each plate, with a total of three plates, which can be represented as three sixes.

Xiaoxiao: I see. Six threes and three sixes mean different things, but they can all be written three times six or six times three.

Teacher: What the students said is perfect. Let's continue to see what the little rabbit and the bird are doing. What formulas can you think of from the picture? Take a pause, have a look, and tell me.

Teacher: What you said is very good. When several identical numbers are added together, we can express them by multiplication. Many problems in life need to be solved by multiplication. Can you give us an example of what can be solved by multiplying three by six?

Taoqi: The question that comes to my mind is that if six trees are planted in one row, how many trees can be planted in three rows? 
老师: 你们观察的真仔细! 这是小松鼠和小猴子带来的松果和桃子. 观察图片. 你能想到哪些算 式? 暂停一下. 想一想, 连一连.

淘气: 我来看松果, 每一个篮子有三个松果. 一共有六个篮子. 也就是六个三相加, 写成加法算 式就是 $3+3+3+3+3+3$.

笑笑：六个三相加也可以写成乘法算式, 三乘六或六乘三（连接图和公式）. 有四张相应的卡片. ......

笑笑: 我发现这两张图（松果和桃子）虽然不同，但都可以写成三乘六或六乘三。这是为什么 呢?

淘气: 左边的松果图, 每个篮子里有三个松果, 一共有六个篮子, 可以用六个三来表示. 右边的桃 子图, 每个盘子上有六个桃子, 一共有三个盘子, 可以用三个六来表示.

笑笑：懂了, 懂了. 六个三和三个六表示的意思不同, 但它们都可以写成三乘六或者六乘三.

老师：同学们说的真好！我们继续看看小兔子和小乌在干什么, 从图中你能想到哪些算式? 暂停 一下, 看一看, 说一说.

老师: 你们说的真好! 当几个相同的数相加时, 我们可以用乘法来表示. 生活中有许多问题需要 用乘法来解决. 你们能举个例子，说明用三乘六可以解决什么问题?

淘气: 我想到的问题是, 如果一排种六棵树, 三排能种多少棵树?

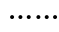

\subsubsection{Summary and consolidation}

Figure 4 is a brief summary and consolidation of the micro class:

\section{English Transcript}

Teacher: How good are you! What did you learn from this lesson?

XiaoXiao: I know that we can handle many real problems with multiplication operations in our daily life.

Multiplication operation plays a critical role in our life.

Teacher: Students are good at learning and summing up. Next, based on what we have learnt, let's do some exercises. Can you help the ant back home? Take a pause. Try to finish first.
Chinese Original Version

老师：同学们真善于思考! 这节课你们学到 了什么?

笑笑: 我知道乘法运算能解决很多我们生活 中的问题. 乘法运算在生活中有重要作用. 老师: 学生真是善于学习和总结. 接下来, 让我们用这些收获做一些练习. 你能帮蚂蚁 回家吗? 暂停一下. 试一试, 练一练. 


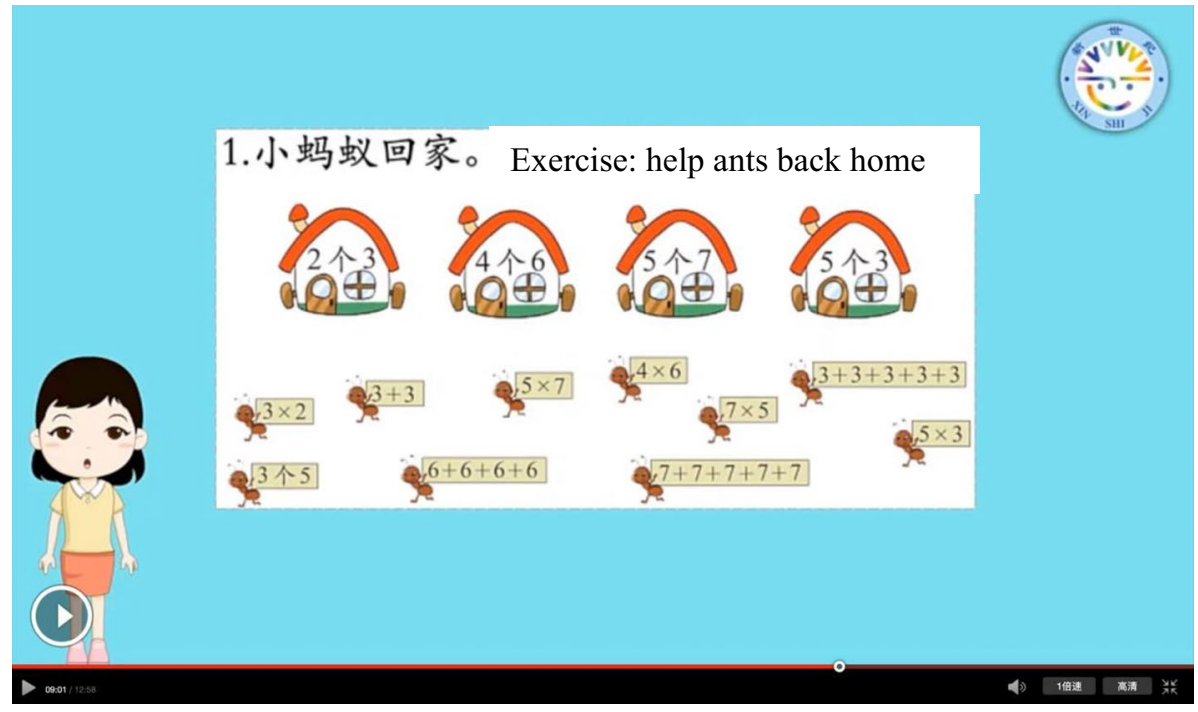

Fig. 4 Summary and consolidation of micro classes

\section{Micro class evaluation criteria: degree of approval}

In the online learning environment during COVID-19, the sense of formality and learning atmosphere of classroom teaching have been weakened and become more dependent on students' self-consciousness (Adedoyin \& Soykan, 2020). Active learners, who hold a positive learning autonomy towards online learning, became the key for students to obtain a good learning outcome (Wang \& Huang, 2020). The most three essential elements are self-planning, self-monitoring, and self-evaluation (Huang et al., 2020). There were plenty of rating scales to evaluate the face-to-face teaching (Benton \& Cashin, 2012). However, there is a lack of attention to online course evaluation (Berk, 2013; Loveland, 2007).

Various studies - mainly focused on micro class evaluation-have provided evidence that student participation in learning was significantly influenced by five dimensions: micro class introduction, learning and teaching interaction, learning summary and consolidation, characteristics of micro class design, and goal attainment (e.g., Bigatel et al., 2012; Drouin, 2012; Li et al., 2016; Terri Rothman, 2011; Thomas \& Graham, 2018; Sun, 2015; Yin, 2015; Young \& Norgard, 2006). First, the introduction is the beginning stage of the micro class teaching process-putting forward teaching goals, creating learning and teaching situations, etc. (e.g., Bigatel et al., 2012; Li et al., 2016; Sun, 2015; Terri Rothman, 2011; Thomas \& Graham, 2018; Yin, 2015). For example, Sun (2015) argued that the micro class evaluation should focus on whether the teaching introduction has made the teaching goal clear. Researchers have found that creating a fascinating learning situation design can stimulate students' interest in learning (e.g., Bigatel, et al., 2012; Terri Rothman, 2011; Thomas \& Graham, 2018). Second, learning and teaching interaction is an indispensable part of the micro class evaluation. Previous studies showed that micro class learning interaction is reflected in the interaction between teachers and students, such as teachers' online questions and students' answers (Thomas \& Graham, 2018). In addition, the suspension of learning micro classes to think about problems and operate teaching aids can also be regarded as a part of elements during the process (e.g., Drouin, 2012; Li et al., 2016; Sun, 2015; Terri Rothman, 2011; Yin, 
2015; Young \& Norgard, 2006). Third, the micro class evaluation must emphasize the summary of learning knowledge and methods and the corresponding consolidation exercises (e.g., Drouin, 2012; Sun, 2015; Terri Rothman, 2011). Fourth, characteristics of micro class design are essential indicators of online course digitization, including picture quality, animation effect, and humanized design (Bigatel et al., 2012; Sun, 2015; Terri Rothman, 2011; Yin, 2015). Finally, the goal achievement of the curriculum standard is another dimension of micro class evaluation. Researchers believed that the realization of curriculum standard requirements is an essential aspect of micro class evaluation (e.g., Drouin, 2012; Li et al., 2016; Sun, 2015; Terri Rothman, 2011; Yin, 2015). Therefore, the evaluation of students' degree of approval towards the NCPM micro class would be based on the above discussed five perspectives: micro class introduction, learning and teaching interaction, learning summary and consolidation, characteristics of micro class design, and goal attainment.

\section{The criteria of perception of digital equity}

With the rapid development of the Internet, the debate on the fairness of online education continues with the growing importance of online education (e.g., Castells, 1996; Hsieh et al., 2008; Lambert, 2020; Van Dijk \& Hacker, 2003; Willems \& Bossu, 2012). During the epidemic period, the fairness of online education has been closely studied by scholars due to the large use of online education (Pittman et al., 2021). On the one hand, scholars who hold digital divide views thought that the application of new technologies increases the existing social stratification and inequality, resulting in a digital divide (Castells, 1996; Van Dijk \& Hacker, 2003). Kaplan (2005), defined education inequity as a measure of the gap between those who are empowered to participate fully in the information and knowledge-based society and economy and those who are not. The development of family digital education resources enlarged the differences in the quality and opportunities of education among different social strata to no small extent, trapping families in the low social strata in an invisible digital gap (Hsieh et al., 2008). On the other hand, the low cost and openness of online courses give them great potential in reducing educational inequality and promoting educational equity (Adedoyin \& Soykan, 2020; Stephens, 2020; Willems \& Bossu, 2012). Lambert (2020) found that MOOCs achieved the goals of student equity and social inclusion, especially for learners with weak skills, low self-confidence, and academic qualifications. According to the above discussion of the digital equity, therefore, we assume that if there is no difference in degree of approval among different social background students, then students' perception of digital equity exists.

Socioeconomic status (SES), region (urban or rural), and gender are always the three main social background factors on the research of digital equity and social inclusion (Lambert, 2020; Willems \& Bossu, 2012). In China, due to the rapid economic development, in a specific stage of development, the differences in family economic conditions are expanding, and the economic development between the east and the west is unbalanced, which leads to differences in education resources and education opportunities (Wang et al., 2014). SES indexes mostly include some quantification of family income, parental education, and occupational status. Research indicated that SES was associated with a wide array of health, cognitive, and socioemotional outcomes in children, with effects beginning before birth and continuing into adulthood (Bradley \& Corwyn, 2002; Letourneau et al., 2011), and it was generally accepted that these processes vary for all children (McLoyd, 1998; Wills et al., 1995). Recently, gender differences in mathematics achievement have become small or even disappeared in largescale assessment (i.e., PISA and TIMSS) in many Western countries but still exist in China. 
Zhu et al. (2018) analyzed the PISA 2015 mathematics data of China's B-S-J-G (representing Beijing-Shanghai-Jiangsu-Guangdong) and found that boys performed far better than girls in the high achievement group. In junior high school and senior high school, boys performed significantly better than girls in mathematics. The difference is greater for senior high school students. Previous studies have focused on the interaction between background variables (i.e., gender and social factors) of face-to-face education (Becker \& McElvany, 2018). Nevertheless, there is little literature on the interaction among online education background variables; thus, we would address the issue in the present study.

The current study aims to explore the student's degree of approval and perception of digital equity of micro classes for primary school-level mathematics in China during COVID-19 by tracking and investigating the NCPM micro class. Specifically, the research questions are as follows:

(a) What is the student's degree of approval with micro classes for primary school-level mathematics in China during the epidemic?

(b) What are students' perceptions of digital equity of micro classes after attending micro classes in China during the epidemic environment?

\section{Methodology}

\subsection{Participants}

To examine students' degree of approval toward micro classes, NCPM organized a largescale online survey after a 2-month learning period with micro classes (see Appendix Table 4). Considering geographical distribution, and school location, using a stratified sampling method, 141,327 Grade 1 to Grade 6 students from 222 primary schools in China were given the survey. The response rate was $94 \%$; finally, 132,740 student responses (boys $52.46 \%$, girls $47.54 \%$ ) were taken into analysis. Of these students, $8.04 \%$ study in rural schools, $91.96 \%$ in urban schools; 19,276 (14.52\%) were primary school students with homes in rural areas, and 113,464 (85.48\%) with homes in urban areas; 73,343 (55.25\%) students were in Grades 1 to 3, and 59,397 (44.75\%) in Grades 4 to 6.

\subsection{Measure}

\subsubsection{Students' degree of approval with the micro classes}

Eight items were developed to test the students' degree of approval on five aspects of the NCPM micro classes: introduction, situation learning interaction, summary and consolidation, characteristics of micro classes design, and goals (see Appendix Table 4 for details of the 18 items). The items were rated on a five-point Likert scale that ranged from 1 (strongly disagree) to 5 (strongly agree). The higher the score is, the greater the students' degree of approval on the micro classes. Tucker-Lewis index (TLI) $=0.970>0.9$, root mean square error approximation $($ RMSEA $)=0.050<0.8$, and standardized root mean square residual $(\mathrm{SRMR})=0.023<0.5$ (Hu \& Bentler, 1999). The internal consistency of each construct was assessed by Cronbach's alpha, composite reliability (CR), and average variance extracted (AVE). There are no absolute threshold values for Cronbach's alpha and composite reliability, but it is suggested that 0.70 or higher indicates evidence of extensive reliability. Moreover, it is recommended that the average variance extracted (AVE) value be higher than 0.5 
(Hair et al., 2013; Henseler et al., 2016). In this study, Cronbach's alpha ranged from 0.804 to 0.905 , CR ranged from 0.804 to 0.905 , and AVE ranged from 0.581 to 0.706 .

\subsubsection{SES, gender, learning location, school location, and previous achievement}

SES is a composite score formed by the highest parental education indicators, highest parental occupation, and home possessions through principal component analysis (OECD, 2017). In the present study, SES was measured by following the three constructs with nine items; for example, parental occupation is coded using the current international standard classification of occupations (ISCO-08). The home's variable books were coded into a fourlevel categorical variable (fewer than or equal to 25 books, 26-100 books, 101-500 books, more than 500 books). Standardized variables were used in the principal component analysis to obtain SES values (OECD, 2017). In the study, an SES value above 0 indicates high SES, and the dummy code is 1 ; an SES value below 0 indicates low SES, and the dummy code is 0 . Gender was measured with one question (dummy code: $0=$ female, $1=$ male). We measured the locations of the students' schools (dummy code: $0=$ rural, $1=$ urban) and the learning locations during the epidemic (dummy code: $0=$ rural, $1=$ urban). In addition, we also investigated the previous achievement of the students (previous academic performance in the last semester) with a five-point Likert scale ranging from 1 (very bad) to 5 (excellent). The higher the score is, the better the student's math performance during the last semester. Then, we recoded the response based on standardized data; the value above 0 indicates higher previous achievement, and the dummy code is 1 ; the value below 0 indicates low previous achievement, and the dummy code is 0 .

\subsection{Data process and analysis}

The questionnaire included three parts: survey notes, personal background information, and degree of approval with the micro class. The participants filled out 37 questions anonymously using an online questionnaire system, Questionnaire Star, and it took approximately 15 min to complete. This study's procedures complied with the provisions of the Declaration of Helsinki regarding research with human participants. Students attended the survey voluntarily with parents' permission and help.

As the data for this study were obtained from 132,740 students in 222 schools, then we calculated the intergroup correlation coefficient of the micro class's effect to see whether multilevel analysis is a necessary, results indicated that the intergroup correlation coefficient of the student's degree of approval was 0.01 , less than the critical value of 0.059 , indicating there was no significant interschool difference in the student's degree of approval; therefore, multilevel analysis is not necessary, and then, ordinary least squares method was used in the present study. First, to determine the differences in student's degree of approval in SES, gender, school location, and learning location, $t$-test was used to perform an overall comparison. Moreover, we examined the differences in student's degree of approval among different groups (e.g., social and economic status, gender, school location, and learning location) in two learning stage (Grades 1-3 and Grades 4-6). The effect sizes of the differences between different groups were reported once the difference was at a statistically significant level.

Second, to investigate the relationship between student's degree of approval and the background variables, such as gender, SES, school location, learning location, and previous achievement, we set up regression model 1: 


$$
A P D E=b_{0}+b_{1} G E N D E R+b_{2} S E S+b_{3} S L O C+b_{4} L L O C+b_{5} P R E A
$$

In model 1, following Aiken and West (1991), we detected the regression of students' gender (GENDER), SES (SES), school location (SLOC), learning location (LLOC), and previous achievement (PREA) in the last semester on student's degree of approval (APDE) with the micro class. When the marginal effect was significant, we calculated its effect size.

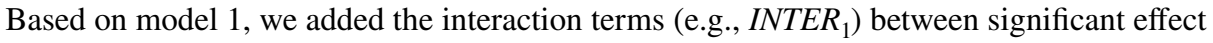
variables, whose marginal effect was significant and effect size was above 0.2 , and other variables to construct moderated model 2 :

$$
A P D E=b_{0}+b_{1} G E N D E R+b_{2} S E S+b_{3} S L O C+b_{4} L L O C+b_{5} P R E A+c_{1} I N T E R_{1}+\ldots+c_{i} I N T E R_{i}
$$

where INTER $R_{1}$ means one of the interaction terms; e.g., GENDER $\times L F$ indicates the interaction term between gender and previous achievement. When the marginal effect of interaction terms is significant, we calculated its effect size.

\section{Findings and discussion}

\subsection{Student's degree of approval with micro classes during COVID-19}

The frequency statistics of the survey items showed that the sum of the "entirely agree" items is approximately $90 \%$. For example, in the survey of "the introduction to the micro class focused on a real-life situation," $34.2 \%$ of primary school students selected "agree." In comparison, $59.4 \%$ of primary school students chose "entirely agree." In the survey of "micro class resources allow us to discuss and communicate with each other," $36.5 \%$ of the primary school students selected "agree," while $56.3 \%$ of the primary school students selected "entirely agreed." The mean and standard deviation values of the micro class's degree of approval are summarized in Table 1 . The average value of the micro class's degree of approval was 4.51, which was approximately $50 \%$ greater than the average of 3 points. The results show that the NCPM micro class has achieved high degree of approval by students during the epidemic period.

\subsection{Difference in student's degree of approval among different groups}

This study compared the differences among the various groups regarding student's degree of approval with the mathematics micro class. First, the variables for the various student clusters were grouped. An independent sample $t$-test was then conducted to compare the differences in student's degree of approval according to the various groups of students. Finally, the effect $\operatorname{size}^{2}$ of the group difference was calculated. Overall, there was a small difference between boys' and girls' micro class degree of approval [4.50(0.46) vs. 4.51(0.46)], $t(131,586)=-3.58, p<0.001, d=0.02$.

The difference on the degree of approval towards the micro classes between low and high family SES students was small though it was significant [low SES group, $M=4.50, \mathrm{SD}=0.45$; high SES group, $\mathrm{M}=4.51, \mathrm{SD}=0.46), t(128,737)=-4.72, p<0.001, d=0.05]$. However, in terms of the school location effect, we found that students who studied at rural school or urban school showed no significant difference on the degree of approval towards NCPM micro

\footnotetext{
2 The calculation formula of the effect is Cohen's d value ES $=(\mathrm{m} 1-\mathrm{m} 2) / \mathrm{s} \_$pooled, where $s \_$pooled is the joint variance. The reference values for small, medium, and large effects are $0.2,0.5$, and 0.8 , respectively.
} 
Table 1 Mean and standard deviation of the student's degree of approval of the micro class

\begin{tabular}{|c|c|c|}
\hline Variables & Mean & $\mathrm{SD}$ \\
\hline Micro class introduction & 4.56 & 0.50 \\
\hline \multicolumn{3}{|c|}{ e.g., "The introduction to the micro class focused on a real-life situation." } \\
\hline Teaching and learning interaction & 4.55 & 0.48 \\
\hline \multicolumn{3}{|c|}{ e.g., "The micro class encourages us to discuss and communicate with each other" } \\
\hline Summary and consolidation & 4.52 & 0.54 \\
\hline \multicolumn{3}{|c|}{ e.g., "Every micro class includes practice links to consolidate and test the content learned." } \\
\hline Characteristics of micro class design & 4.55 & 0.52 \\
\hline \multicolumn{3}{|c|}{$\begin{array}{l}\text { e.g., "Taoqi, Xiaoxiao, a smart old man, a smart dog, etc., are part of the instruction for } \\
\text { every micro class." }\end{array}$} \\
\hline Goal attainment & 4.37 & 0.58 \\
\hline \multicolumn{3}{|c|}{$\begin{array}{l}\text { e.g., "The micro class teaching and lessons promote my understanding and mastery of math } \\
\text { concepts." }\end{array}$} \\
\hline Total & 4.51 & 0.46 \\
\hline
\end{tabular}

$N=132,740$

classes [rural $4.51(0.46)$ vs. urban $4.51(0.46), t(12,619)=0.46, p>0.05]$, in addition, students' learning location during the social isolation period also showed no impact on students' degree of approval, specifically, students learning in rural or in urban area perceived the same degree of approval level on NCPM micro classes [rural $\mathrm{M}=4.51, \mathrm{SD}=0.46$; urban $\mathrm{M}=4.51$, $\mathrm{SD}=0.46 ; t(26,536)=-1.21, p>0.05]$. Based on the above results, we found there were no significant difference in student's degree of approval among different groups (i.e., gender, school location, and learning location during the social isolation). Furthermore, the results revealed a significant difference in degree of approval between students with a high previous achievement $(\mathrm{M}=4.59, \mathrm{SD}=0.44)$ and those with a low previous achievement $(\mathrm{M}=4.47$, $\mathrm{SD}=0.46), t(89,652)=-47.58, p<0.001, d=0.30$, indicating that the better the previous achievement, the greater the degree of approval on NCPM micro classes.

Furthermore, the differences in student's degree of approval in SES, gender, school location, learning location during social isolation, and previous achievement were tested in detail in every learning stage (first stage, Grades 1 to 3; second stage, Grades 4-6). As reflected in Table 2, in the first stage (Grades 1 to 3), there is no significant difference in degree of approval between female and male, and different school location, either. Nevertheless, the difference in degree of approval varied in different SES group and students' learning location during social isolation period, but the effect size is less than 0.2 . In the second stage (Grades 4 to 6), significant difference in degree of approval was not found among students' school location and learning location during the epidemic, and SES group, but gender difference with very small effect size was found. We also found that there is a significant difference in student's degree of approval in previous achievement in learning stage 1 and learning stage 2 . This result means that during the epidemic, the home study micro class better met most groups of students' perceived needs. 


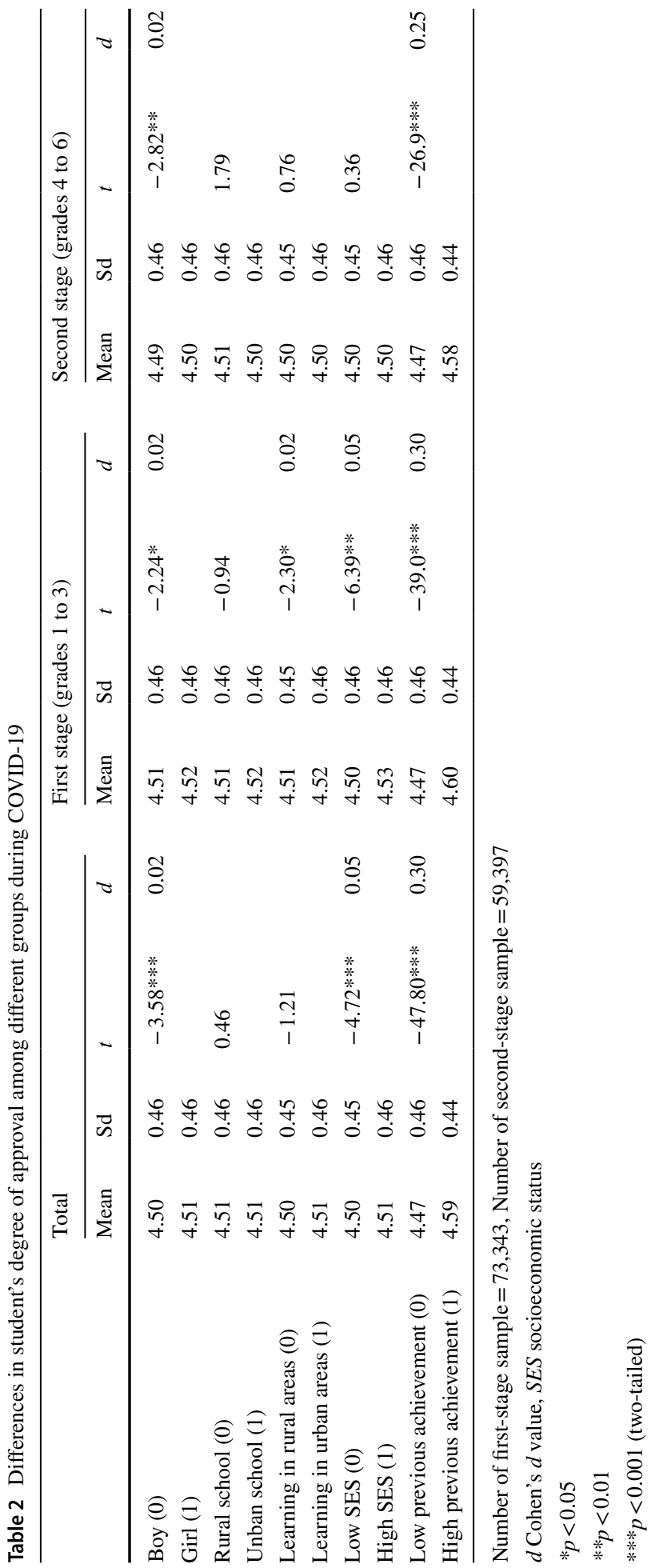




\subsection{Link between student's degree of approval and background factors}

The results of the regression model are shown in Table 3 (see model 1). The results indicated that gender $(\beta=0.01, p<0.001)$, SES $(\beta=-0.01, p<0.001)$, school location $(\beta$ $=-0.02, p<0.05)$, and previous achievement $(\beta=0.13, p<0.001)$ significantly predict student's degree of approval, while students' learning location cannot significantly predict student's degree of approval. By calculating the effect size of variables with significant marginal effect, it is found that only the effect size $(d=0.28)$ of students' previous achievement is greater than 0.2. Overall, primary school students' background variables explain approximately $1.68 \%$ of the variance in student's degree of approval.

Moreover, the background variables such as the previous achievement can significantly predict the student's degree of approval in model 1 to investigate the relationship between student's degree of approval and interactions. Based on model 1, the interaction terms of four students' previous achievements and each other variable are added to construct model 2 . Four interactions were found in model 2-gender $\times$ previous achievement interaction $(\beta=0.01, p>0.05), \mathrm{SES} \times$ previous achievement interaction $(\beta=0.01, p>0.05)$, school location $\times$ previous achievement interaction $(\beta=-0.02, p>0.05)$, learning location $\times$ previous achievement interaction $(\beta=0.01, p>0.05)$ - that cannot significantly predict student's degree of approval. Furthermore, compared with model 1, the explanatory effect size of

Table 3 Regression model and moderated model of student's degree of approval during COVID-19

\begin{tabular}{|c|c|c|c|c|}
\hline & \multicolumn{2}{|l|}{ Model 1} & \multicolumn{2}{|l|}{ Model 2} \\
\hline & Coefficient & $\mathrm{ES}^{\mathrm{a}}$ & Coefficient & ES \\
\hline Intercept & $4.48 * * *$ & & $4.48 * * *$ & \\
\hline \multicolumn{5}{|l|}{ Independent variables } \\
\hline Gender & $0.01 * * *$ & 0.02 & $0.01 *$ & 0.02 \\
\hline SES & $-0.01 * * *$ & 0.02 & $-0.01 * * *$ & 0.03 \\
\hline School location & $-0.02 *$ & 0.03 & -0.01 & \\
\hline Learning location & -0.00 & & -0.00 & \\
\hline Previous achievement & $0.13^{* * *}$ & 0.28 & $0.13 * * *$ & 0.28 \\
\hline \multicolumn{5}{|l|}{ Interactions } \\
\hline Gender $\times$ previous achievement & & & 0.01 & \\
\hline $\mathrm{SES} \times$ previous achievement & & & 0.01 & \\
\hline School location $\times$ previous achievement & & & -0.02 & \\
\hline Learning location $\times$ previous achievement & & & 0.01 & \\
\hline Standard deviation & 0.454 & & 0.454 & \\
\hline Degrees of freedom & 132,734 & & 132,730 & \\
\hline R-squared & $1.68 \%$ & & $1.68 \%$ & \\
\hline
\end{tabular}

In model 1, gender, SES, school location, learning location, and previous achievement were used to regress the student's degree of approval. Because previous achievement is an effective predictor of model 1 , the interaction between previous achievement and other variables is added in model 2

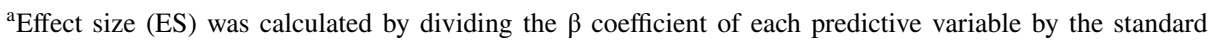
deviation of the estimated results in model 1: 0.454

$* p<0.05$

$* * p<0.01$

$* * * p<0.001$ 
model 2 did not increase, which also showed that the interaction between variables was not significant. The analysis indicated that gender, SES, school location, and learning location of primary school students do not significantly predict student's degree of approval. The previous achievement of primary school students has significant predictive ability. There is no significant interaction between these variables during the COVID-19 pandemic.

\section{Conclusions}

Due to the outbreak of COVID-19, online mathematics teaching has become the primary teaching method to respond to the epidemic and protect life. Micro classes are widely used in many countries including China. This study investigated Chinese primary school student's degree of approval with the NCPM micro class under the epidemic environment. Gender, SES, school location, learning location, and previous achievement were considered to test the perception of digital equity of the primary school mathematics micro class. In response to the first research goal of this study, we found that primary school students had a high degree of approval towards the NCPM micro classes, consistent with the meta-analysis of Lambert (2020). One possible reason why primary school students hold a high approval of micro class teaching is that the design of NCPM micro class was totally based on the NCPM textbook, which students are quite familiar with. Another explanation may be that during the epidemic period, primary school students were isolated at home and had less learning opportunities, so they suffered from learning anxiety and then had a strong eagerness to learn. The emergence of online mathematics teaching (e.g., NCPM micro classes), to a certain degree, may satisfy the students' psychological demands of mathematics learning and thus hold a positive approval towards that. We also found that when micro class teaching process with a real situation which children are familiar with, primary school student's degree of approval is often higher through problem driving, learning interaction, independent inquiry, discovering mathematical knowledge, and solving mathematical problems.

Furthermore, students' perception of digital equity is an urgent problem, especially during the epidemic period. Regarding the second research goal of this study, we found that there was no significant difference in gender, SES, school location, learning location at home, etc., indicating digital equity. Previous studies have shown that traditional face-to-face mathematics education is not equal due to factors related to SES, gender, school location, and other conditions (Wang et al., 2014; Zhu et al., 2018). On the one hand, the rise of online mathematics education is prone to the digital divide (Castells, 1996; Van Dijk \& Hacker, 2003); on the other hand, it also provided new opportunities to narrow inequity in mathematics education (Lambert, 2020; Willems \& Bossu, 2012). This study found that during the epidemic period, the positive effect of online teaching of primary school mathematics (e.g., micro class) in perception of digital equity versus negative effect, which could provide a solution to improve the fairness of traditional face-to-face instruction; for example, we can make full use of high-quality online mathematics teaching resources [e.g., micro classes and massive open online courses (MOOCs)] in face-to-face instruction and solve the problem of unfair education opportunities caused by the lack of school teaching resources or the loss of high-quality teachers.

The main contribution and innovation of the study are as follows: first, we developed a series of NCPM micro classes and took the NCPM micro class as an example to investigate the use of these classes under the epidemic and we also showed the teaching process of primary school mathematics micro classes through an example. Second, to our limited experience, this was the first attempt with large-scale survey data to analyze the primary school 
student's degree of approval toward mathematics micro class teaching under COVID 19. Lastly, we also investigated the problem perception of digital equity in primary school students' online mathematics teaching. Hopefully the research will give some enlightenment to mathematics education practice towards the world.

\section{Appendix}

Table 4 Students' degree of approval of a mathematics micro class

\section{Items}

1 Before the class, the micro class reminds me to prepare my learning tools

2 Each micro class clearly defines the learning goals before learning new content

3 The micro class focuses teaching using real-life situations

4 The teaching of the micro class is child-friendly and easy to understand

5 The explanations of important content in the micro class are clear, vivid, and concise

6 The micro class encourages us to discuss and communicate with each other

7 The micro class presents errors and confusion to which students are prone and discusses the causes of the errors and confusion

8 Each micro class is arranged with practice sessions to consolidate and test what you have learned

9 Each micro class is arranged with a summary link to encourage us to share our learning gains

10 The duration of each micro class is controlled: 8-10 min per lesson for Grades 1 and 2; 10-12 min per lesson for Grades 3 and 4; 12-15 min per lesson for Grades 5 and 6

11 Taoqi, Xiaoxiao, intelligent older people, smart dogs, etc. accompany us as we participate in every micro class

12 The auto-pause function of the micro class helps guide us to think about mathematics and practice mathematics offline $(\mathrm{R})$

13 Unlike during the school period, when learning mathematics through a micro class, I can choose to look back on important content and content that was covered too quickly, which helps me meet my learning needs

14 The micro class focuses on a combination of our online and offline learning

15 Learning through the micro class promotes my understanding and grasp of mathematical concepts (R)

16 Learning through the micro class promotes my independent thinking (R)

17 Learning through the micro class helps me to comprehensively use knowledge to solve real-world problems

18 Learning through the micro class stimulates my curiosity about mathematics (Likert's scale 1, strongly disagree; 5 , strongly agree)

Acknowledgements We would like to thank the reviewers for their meaningful and insightful suggestions regarding previous versions of this paper. We also want to thank our peers Dan Zhang, Huiying Hou, Xue Zheng, Xiaofeng Du, Zhe Wang, Lihong Ma, and Da Zhou and the project participants for providing us with images and data. 


\section{References}

Adedoyin, O. B., \& Soykan, E. (2020). Covid-19 pandemic and online learning: The challenges and opportunities. Interactive Learning Environments. https://doi.org/10.1080/10494820.2020.1813180

Aiken, L. S., \& West, S. G. (1991). Multiple regression: Testing and interpreting interactions. Sage.

Becker, M., \& McElvany, N. (2018). The interplay of gender and social background: A longitudinal study of interaction effects in reading attitudes and behavior. British Journal of Educational Psychology, 88(4), 529-549. https://doi.org/10.1111/bjep.12199

Bedford, J., Enria, D., Giesecke, J., Heymann, D. L., Ihekweazu, C., Kobinger, G., Lane, H. C., Memish, Z., Oh, M. D., Schuchat, A., Ungchusak, K., \& Wieler, L. H. (2020). COVID-19: Towards controlling of a pandemic. The Lancet, 395(10229), 1015-1018. https://doi.org/10.1016/S0140-6736(20)30673-5

Benton, S. L., \& Cashin, W. E. (2012). Student ratings of teaching: A summary of research and literature (pp. 1-19). IDEA Center Kansas State University.

Berk, R. A. (2013). Face-to-face versus online course evaluations: A “consumer's guide" to seven strategies. Journal of Online Learning and Teaching, 9(1), 140.

Bigatel, P. M., Ragan, L. C., Kennan, S., May, J., \& Redmond, B. F. (2012). The identification of competencies for online teaching success. Journal of Asynchronous Learning Network, 16(1), 59-78. https://doi. org/10.24059/olj.v16i1.215

Bradley, R. H., \& Corwyn, R. F. (2002). Socioeconomic status and child development. Annual Review of Psychology, 21(3), 371-399. https://doi.org/10.1177/1063426611421007

Castells, M. (1996). The rise of the network society. Blackwell.

Drouin, M. (2012). What's the story on evaluations of online teaching? In M. E. Kite (Ed.), Effective evaluation of teaching: A guide for faculty and administrators (pp. 60-70). Society for the Teaching of Psychology.

Fang, X., \& Liu, R. (2017). Determinants of teachers' attitude toward microlecture: Evidence from elementary and secondary schools. Eurasia Journal of Mathematics, Science and Technology Education. https://doi.org/10.12973/eurasia.2017.01013a

Gao, L., Gao, X., Xie, Y., \& Zhang, M. (2019). Retrospection and reflection: The study of learning effect about 'micro-lecture'-the meta-analysis of 38 studies at home and abroad (in Chinese). Modern Distance Education, 1, 37-45.

Gong, X., \& Zhu, W. (2014). Teaching design practice of micro class based on knowledge point. 2014 International Conference on Advanced ICT (ICAICTE-2014) (pp. 94-98). Atlantis Press.

Hair, J. F., Hult, G. T. M., Ringle, C. M., \& Sarstedt, M. (2013). A primer on partial least squares structural equation modeling (PLS-SEM). Sage.

Henseler, J., Hubona, G., \& Ray, P. A. (2016). Using PLS path modeling in new technology research: Updated guidelines. Industrial Management \& Data Systems, 116(1), 2-20. https://doi.org/10.1108/ imds-09-2015-0382

Hsieh, J., Rai, A., \& Keil, M. (2008). Understanding digital inequality: Comparing continued use behavioral models of the socio-economically advantaged and disadvantaged. Mis Quarterly, 32(1), 97-126.

Hu, L. T., \& Bentler, P. M. (1999). Cutoff criteria for fit indexes in covariance structure analysis: Conventional criteria versus new alternatives. Structural Equation Modeling, 6(1), 1-55. https://doi.org/10. $1080 / 10705519909540118$

$\mathrm{Hu}, \mathrm{S} .$, \& Wen, C. (2016). Analysis on the current situation and trend of micro class research in China. Distance Education in China, 8, 46-53. https://doi.org/10.3969/j.issn.1009-458X.2016.08.007 in Chinese.

$\mathrm{Hu}, \mathrm{T}$. (2011). "Micro class": A new trend of the development of regional educational information resources. e-Education Research, 10, 61-65. https://doi.org/10.13811/j.cnki.eer.2011.10.020 in Chinese.

$\mathrm{Hu}, \mathrm{T}$., \& Zhan, C. (2012). Regional practice and enlightenment of high quality "micro class" resource development in primary and secondary schools. China Education Info, 22, 65-69. in Chinese.

Huang, R., Wang, Y., Wang, H., Lu, X., \& Gao, B. (2020). New teaching form of future education: Flexible teaching and active learning. Research on Modern Distance Education, 32(03), 3-14. https://doi.org/ 10.3969/j.issn.1009-5195.2020.03.001 in Chinese.

Jiang, Y. (2013). Systematic analysis of microlecture research and development trend. Distance Education in China, 12, 64-73. https://doi.org/10.3969/j.issn.1009-458X.2013.12.011 in Chinese.

Jiao, J., Zhou, X., \& Chen, Z. (2020). Case analysis of the online instruction in the context of "classes suspended but learning continues" for plague prevention. China Educational Technology, 3, 106-113. in Chinese. 
Kaplan, D. (2005). e-Inclusion: New challenges and policy recommendations (Report prepared by the Expert Section of the Europe Advisory Group, European Commission). Retrieved from http://ec. europa.eu/information_society/eeurope/2005/doc/all_about/kaplan_report_einclusion_final_version. pdf

Kuhfeld, M., Soland, J., Tarasawa, B., Johnson, A., Ruzek, E., \& Liu, J. (2020). Projecting the potential impact of COVID-19 school closures on academic achievement. Educational Researcher, 49(8), 549565. https://doi.org/10.3102/0013189x20965918

Lambert, S. R. (2020). Do MOOCs contribute to student equity and social inclusion? A systematic review 2014-18. Computers \& Education, 145(17), 103693. https://doi.org/10.1016/j.compedu.2019.103693

Letourneau, N. L., Duffett-Leger, L., Levac, L., Watson, B., \& Young-Morris, C. (2011). Socioeconomic status and child development: A meta-analysis. Journal of Emotional and Behavioral Disorders, 21(3), 211-224. https://doi.org/10.1177/1063426611421007

Li, C. B., \& Liu, L. F. (2015). The design and development of mathematics microlecture for elementary school. In J. Ding (Ed.), Proceedings of the 2015 international conference on computer science and intelligent communication (Vol. 16, pp. 485-487). Atlantis Press.

Li, P., Zuo, Y., Liu, Z., \& Ge, Y. (2016). Construction and implementation of micro class evaluation index system. Teaching \& Administration, 16, 74-76. in Chinese.

Liu, S., Yang, L., Zhang, C., Xiang, Y.-T., Liu, Z., Hu, S., \& Zhang, B. (2020). Online mental health services in China during the COVID-19 outbreak. The Lancet Psychiatry, 7(4), e17-e18. https://doi.org/ $10.1016 / \mathrm{s} 2215-0366(20) 30077-8$

Loveland, K. A. (2007). Student evaluation of teaching (SET) in web-based classes: Preliminary findings and a call for further research. Journal of Educators Online. https://doi.org/10.9743/JEO.2007.2.4

McLoyd, V. C. (1998). Socioeconomic disadvantage and child development. American Psychologist, 53(2), 185-204. https://doi.org/10.1037/0003-066X.53.2.185

MOE. (2020). Using the internet platform "classes suspended but learning continues". Retrieved from http://www.moe.gov.cn/jyb_xwfb/gzdt_gzdt/s5987/202001/t20200129_416993.html

Moorhouse, B. L. (2020). Adaptations to a face-to-face initial teacher education course 'forced' online due to the COVID-19 pandemic. Journal of Education for Teaching, 46(4), 609-611. https://doi.org/10. $1080 / 02607476.2020 .1755205$

NCPMTEC. (2020). New century mathematics micro lecture 3.0: Different companionship in special period. Retrieved from https://www.sohu.com/a/392173914_653832

OECD. (2017). PISA 2015 Technical Report. https://www.oecd.org/pisa/data/2015-technical-report/

Pittman, J., Severino, L., DeCarlo-Tecce, M. J., \& Kiosoglous, C. (2021). An action research case study: Digital equity and educational inclusion during an emergent COVID-19 divide. Journal for Multicultural Education. https://doi.org/10.1108/jme-09-2020-0099

Stephens, R. C. (2020). How online education can be used to improve equity of access in high school courses in Southern California: A qualitative study. Available from ProQuest Dissertations \& Theses Global.

Sun, P. (2015). The design of micro class evaluation system based on user experience. Modern Educational Technology, 25(03), 63-68. https://doi.org/10.3969/j.issn.1009-8097.2015.03.010 in Chinese.

Terri Rothman, L. R., Brennan, M., \& Mitchell, D. (2011). Criteria for assessing student satisfaction with online courses. International Journal for e-Learning Security, 1(1), 27-32. https://doi.org/10.20533/ ijels.2046.4568.2011.0004

Thomas, J. E., \& Graham, C. R. (2018). Online teaching competencies in observational rubrics: What are institutions evaluating? Distance Education, 40(1), 114-132. https://doi.org/10.1080/01587919.2018. 1553564

Van Dijk, J., \& Hacker, K. (2003). The digital divide as a complex and dynamic phenomenon. The Information Society, 19(4), 315-326. https://doi.org/10.1080/01972240309487

Wang, L., Li, X., \& Li, N. (2014). Socio-economic status and mathematics achievement in China: A review. ZDM-Mathematics Education, 46(7), 1051-1060. https://doi.org/10.1007/s11858-014-0617-8

Wang, S., \& Huang, R. (2020). The generation mechanism and promotion strategy of online active learning willingness. Open Education Research, 5, 99-110. https://doi.org/10.13966/j.cnki.kfjyyj.2020.05.010 in Chinese.

WHO. (2020). Coronavirus disease (COVID-19) outbreak situation (Last update: 30 May 2020, 08:00 GMT+8). Retrieved from https://www.who.int/emergencies/diseases/novel-coronavirus-2019

Willems, J., \& Bossu, C. (2012). Equity considerations for open educational resources in the glocalization of education. Distance Education, 33(2), 185-199. https://doi.org/10.1080/01587919.2012.692051

Wills, T. A., Mcnamara, G., \& Vaccaro, D. (1995). Parental education related to adolescent stress-coping and substance use: Development of a mediational model. Health Psychology, 14(5), 464-478. https:// doi.org/10.1037/0278-6133.14.5.464 
Xie, G. (2015). Analysis of five relationships among MOOC, flipped classroom, micro class and microvideo. Education Science, 31(5), 94-94. https://doi.org/10.3969/j.issn.1672-0008.2013.04.005 in Chinese.

Yin, H. (2015). Design and evaluation of micro class. Modern Educational Technology, 25(01), 46-52. https://doi.org/10.3969/j.issn.1009-8097.2015.01.007 in Chinese.

Young, A., \& Norgard, C. (2006). Assessing the quality of online courses from the students' perspective. Internet \& Higher Education, 9(2), 107-115. https://doi.org/10.1016/j.iheduc.2006.03.001

Zhu, Y., Kaiser, G., \& Cai, J. (2018). Gender equity in mathematical achievement: The case of China. Educational Studies in Mathematics, 99(3), 245-260. https://doi.org/10.1007/s10649-018-9846-Z

Zhu, Z., Guo, S., Wu, D., \& Liu, S. (2020). Interpretation, key problems and Countermeasures of the policy of "Classes suspended but learning continues." China Educational Technology, 2020, 1-7. in Chinese.

Publisher's Note Springer Nature remains neutral with regard to jurisdictional claims in published maps and institutional affiliations. 